Provided for non-commercial research and education use. Not for reproduction, distribution or commercial use.

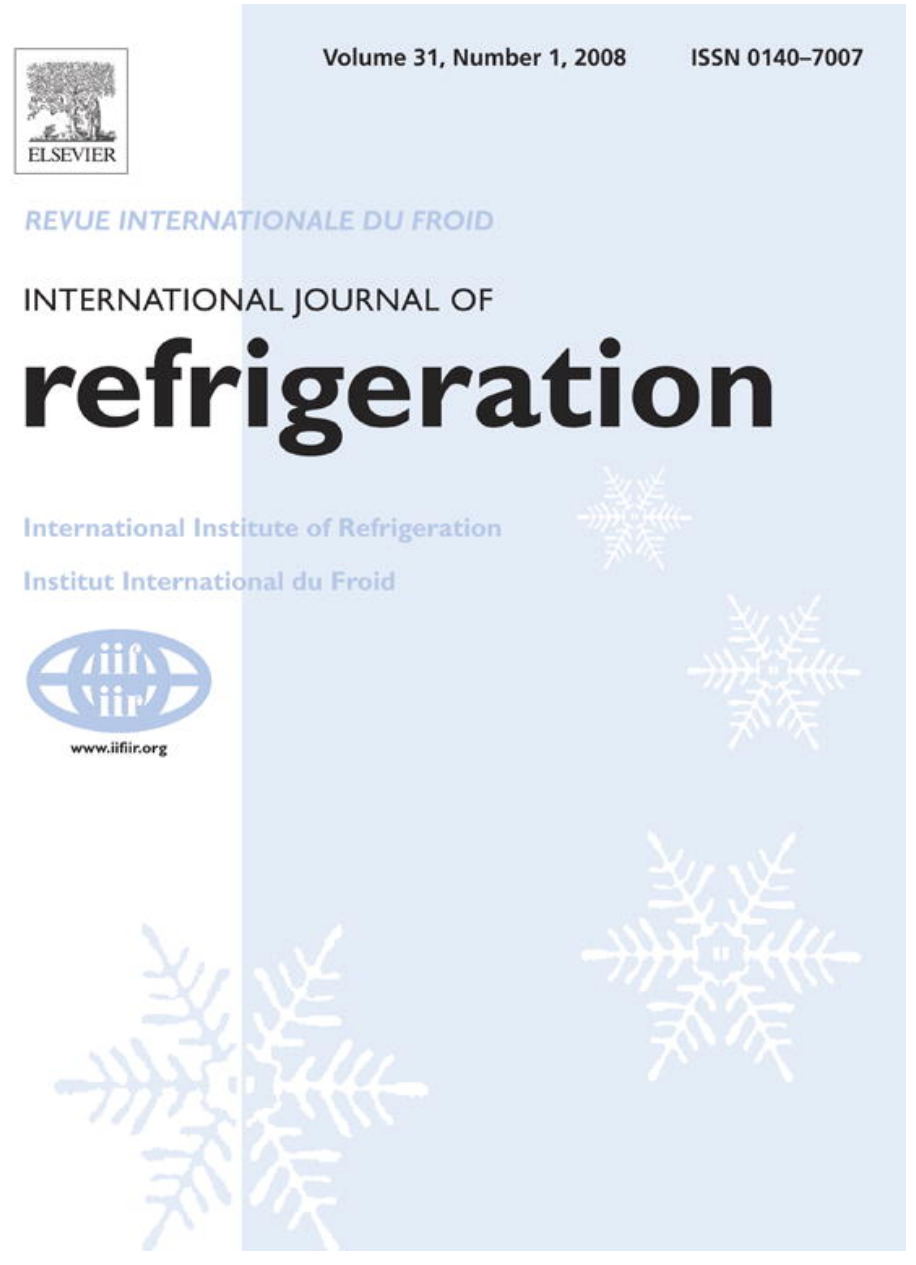

This article was published in an Elsevier journal. The attached copy

is furnished to the author for non-commercial research and education use, including for instruction at the author's institution, sharing with colleagues and providing to institution administration.

Other uses, including reproduction and distribution, or selling or licensing copies, or posting to personal, institutional or third party websites are prohibited.

In most cases authors are permitted to post their version of the article (e.g. in Word or Tex form) to their personal website or institutional repository. Authors requiring further information regarding Elsevier's archiving and manuscript policies are encouraged to visit:

http://www.elsevier.com/copyright 


\title{
Refrigerant flow instability as a means to predict the need for defrosting the evaporator in a retail display freezer cabinet
}

\author{
J.M.W. Lawrence ${ }^{a, *}$, J.A. Evans ${ }^{b}$ \\ ${ }^{\mathrm{a} J T L}$ Systems Ltd, 41 Kingfisher Court, Hambridge Road, Newbury, Berkshire RG14 5SJ, UK \\ ${ }^{\mathrm{b}}$ Food Refrigeration and Process Engineering Research Centre, University of Bristol, \\ Churchill Building, Langford, Bristol BS40 5DU, UK
}

\section{A R T I C L E I N F O}

\section{Article history:}

Received 17 July 2006

Received in revised form

15 March 2007

Accepted 4 May 2007

Published online 11 August 2007

Keywords:

Display cabinet

Survey

Defrosting

Energy consumption

Experiment

Software

\begin{abstract}
A B S T R A C T
For refrigerated display cabinets to perform their function of keeping food cold, there must be free movement of air through the evaporator. The moisture in the ambient air entrained in the cabinet forms frost on the evaporator. It is traditional for heat to be applied to the evaporator at regular intervals to melt this frost. The frequency, typically $3-4$ times per day, is enough to avoid the frost becoming excessive even in extreme conditions. For much of the time defrosting is not always necessary. A large portion of the energy used during a defrost is an overhead - heating and then cooling the metal and the food rather than melting the frost. The effect of this is examined in the paper along with the results from testing an algorithm that detects the need for a defrost from the pattern of refrigerant flow (or evaporator exit superheat). The algorithm allows the number of defrosts to be reduced without excessively raising the temperature of food stored in the cabinet. The reduction in energy and carbon dioxide emission were examined and were shown to be substantial.
\end{abstract}

(c) 2007 Elsevier Ltd and IIR. All rights reserved.

\section{L'instabilité de l'écoulement du frigorigène comme moyen de prévision des moments où le dégivrage s'avère nécessaire : application à un congélateur utilisé pour la vente au détail}

Mots clés : Meuble de vente ; Enquête ; Dégivrage ; Consommation d'énergie ; Expérimentation ; Logiciel

\section{Introduction}

In commercial refrigeration, display cabinets are used to present the product on sale to the customers and to maintain quality and microbial safety of the product. Irrespective of cabinet type, air will be entrained into the cabinet at some stage of its use. This may be intermittent (as in glass door units) or continuous (as in open units). The entrained ambient

\footnotetext{
* Corresponding author. Tel.: +44 1635 263615; fax: +44 1635263647.

E-mail address: mike.lawrence@jtl.co.uk (J.M.W. Lawrence). 0140-7007/\$ - see front matter (c) 2007 Elsevier Ltd and IIR. All rights reserved. doi:10.1016/j.ijrefrig.2007.05.015
} 


\begin{tabular}{|c|c|}
\hline \multicolumn{2}{|c|}{ Nomenclature $^{1}$} \\
\hline$S_{1}$ & lowest but one of the 16 readings (i.e. reading 2 ) \\
\hline$S_{2}$ & highest but one of the readings (i.e. reading 15 ) \\
\hline$S_{m}$ & mean of the ranked readings $2-15$ \\
\hline $\mathrm{V}$ & $\begin{array}{l}\text { volatility - a measure of the recent variation in } \\
\text { superheat }\end{array}$ \\
\hline LRV & $\begin{array}{l}\text { Long Run Volatility - the mean of the volatility } \\
\text { since the last defrost }\end{array}$ \\
\hline I & $\begin{array}{l}\text { integral - accumulates when } V>\text { LRV. Sets back } \\
\text { to zero when } V<L R V\end{array}$ \\
\hline \multicolumn{2}{|c|}{$\begin{array}{l}Q_{\text {steadystate }} \text { Heat removed from cabinet in steady state } \\
\text { conditions }\end{array}$} \\
\hline Qexcess & $\begin{array}{l}\text { integral of heat removed from cabinet after de- } \\
\text { frost in excess of that which would be removed } \\
\text { in steady state conditions }\end{array}$ \\
\hline$m$ & mass of refrigerant passing through circuit \\
\hline$h_{2}$ & enthalpy of refrigerant at evaporator exit \\
\hline$h_{1}$ & enthalpy of refrigerant at cabinet entry \\
\hline
\end{tabular}

air has a high water content and because the cabinet is at a lower temperature than the dew point of the ambient air the water in the air will condense within the cabinet. This water will preferentially condense on the evaporator because it is the lowest temperature surface in the cabinet and freeze, because the temperature is below $0{ }^{\circ} \mathrm{C}$. This results in the evaporator needing to be heated periodically to disperse the frost. If it is not done sufficiently frequently, frost can build up on the evaporator.

Refrigerated storage of food accounts for $40-60 \%$ of the energy used in supermarkets (Axell and Fahlen, 2002). For a typical size food retail store, $3500 \mathrm{MWh}$ of electrical energy will be consumed per annum (Stribling et al., 1997), of which 2100 MWh can be due to the refrigeration systems. A significant amount of energy in supermarkets is used to defrost cabinets (Gage and Kazachki, 2002; Datta and Tassou, 2002a). Howell et al. (1999) have reported that depending on store size, humidity in the store and cabinet types the energy associated with defrosts and anti-sweat heaters can exceed $30 \%$ of the total refrigeration electrical energy in a supermarket. It has also been recognised that defrosts are deleterious to the shelf-life of the food in the cabinet. This is because food temperatures are raised due to the heat added during the defrost. Further disadvantages of defrosting occur because temperature cycling of food promotes weight loss and causes deterioration in appearance (Fu and Labuza, 1997).

Deposition of frost on the evaporator is initially favourable as it reduces fin-tube contact resistance and the rough frosted surface acts as a fin, thus temporarily increasing the air-side heat transfer coefficient (Padki et al., 1989). However, as the frost thickens the insulating effect becomes dominant, the heat transfer rate is reduced, the air-side pressure drop across the evaporator increases which ultimately decreases the air flow rate and increases the infiltration of warm and humid store air into the cabinet.

\footnotetext{
${ }^{1}$ Superheat readings are taken over $16 \mathrm{~min}$. These are ranked lowest to highest.
}

Several methods to defrost evaporators are employed in retail cabinets. Chilled cabinets are often defrosted during an 'off-cycle' where the ice on the evaporator is allowed to melt naturally during periods when the cabinet refrigeration system is off. This method although not using any direct energy to melt the ice can only be used in chilled cabinets as the air passing over the evaporator needs to be above $0{ }^{\circ} \mathrm{C}$ to allow the ice to melt. Other means of defrost that can be used in frozen as well as chilled cabinets are electric where resistive heaters are placed either in front of, or embedded in, the coil block and hot or cool gas where gas is taken from the compressor or receiver is passed through the evaporator.

Usually defrosts are scheduled at pre set times (every 6 or $8 \mathrm{~h}$ would be typical) and this can result in unnecessary defrosts and excess energy use and increase in product temperatures. The defrost is most usually terminated on a temperature or time setting, whichever occurs first, although it is generally good practice to terminate on temperature to ensure all the ice have melted. Axell and Fahlen (2002) have recognised that a number of factors affect defrost demand, i.e. ambient temperature and humidity around a cabinet, evaporating temperature, customer activity, ventilation system disturbance, stored quantity of food and its spatial distribution and temperature, and state of the food recently loaded. Various studies carried out on chilled cabinets by Datta et al. (1998), Datta and Tassou (1998), and Tassou et al. (2001) reported that when environmental temperature is reasonably constant, the relative humidity was the primary parameter influencing frost formation and that the enthalpy of the ambient air could be used to control defrosts. In their study they found differences between the defrost requirements for cabinets during summer and winter and measured condensate removed from cabinet in a UK store at $4 \mathrm{l}$ per defrost in winter and $7.5 \mathrm{l}$ per defrost in summer. Various parameters influencing the need to defrost will be transient and cabinet specific. Therefore ideally the demand for defrosts should be continuously established for each cabinet individually.

Clearly, if the level of evaporator frosting can be determined in real time, defrosts can be limited to only those times when they are required. There have been various attempts at this using artificial intelligence techniques (Datta and Tassou, 1999), neural networks (Datta and Tassou, 2002b), air pressure difference (Heinzen, 1988), temperature difference between air and evaporator surface (Ciricillo, 1985; Buick et al., 1978), measurement of parameters around evaporator and in ambient air near cabinet (Kuwahara, 1985), fan power sensing (Muller, 1975), comparing the heat transfer rate on the air and refrigerant side of the evaporator (Thybo et al., 2002) and measuring ice thickness (by measurement of the thermal conductivity of ice) (Llewelyn, 1984; Woodley, 1989; Paone and Rossi, 1991). In general no previous defrost on demand system has gained widespread acceptance due to the complexity of sensing methods, reliability and cost (Howell et al., 1999).

As reported by Lawrence and Parker (2001), a novel means of detecting the need for a defrost called PREDICT (Pattern Recognition Enables Defrost Initiation at Correct Time) has been developed. PREDICT is based on detecting instability in the flow of refrigerant into the evaporator. This instability is caused by the Thermostatic Expansion Valve (TEV) being unable to control refrigerant flow adequately once frost build 
up develops on the evaporator. Unstable conditions begin to develop due to thermal resistance between the evaporator core and the air due to the frost build up. As an evaporator ices up, the amount of heat that can be removed by it decreases. This means that the amount the TEV can open without causing liquid to flow out of the exit of the evaporator decreases. This can also be viewed as lessening the superheat at the evaporator exit for any given flow, or position of the bellows in the TEV. In the iced condition, the TEV is unable to control refrigerant flow through the evaporator in a stable manner. The valve opens in response to high superheat at the exit of the evaporator but then has to close rapidly as the superheat is quickly reduced. This results in valve instability or 'hunting' where the valve opens and closes rapidly to try and maintain the set level of superheat. The purpose of the work, reported here, was to prove the validity of the PREDICT method and to establish the level of energy savings that could be expected in a frozen retail display cabinet.

\section{Experimental set up and methodology}

\subsection{Test room and cabinet}

The tests were carried out in a test room conforming to EN441 standards and climate class III (temperature of $25^{\circ} \mathrm{C}$ and relative humidity of $60 \%$ ) or IV (temperature of $30^{\circ} \mathrm{C}$ and relative humidity of 55\%) (EN441-4, 1995; EN441-5, 1996; EN441-6, 1995; EN441-9, 1996; EN441-12, 1996). A $2.5 \mathrm{~m}$ frozen food well display cabinet was installed into the test room and connected to a remote compressor and operated with refrigerant R404A. The cabinet was loaded with standard test packs (consisting of $200 \times 100 \times 50 \mathrm{~mm}$ and $100 \times 100 \times 50 \mathrm{~mm}$ parallelepiped packs filled with oxyethylmethyl cellulose), as specified in EN441-5 (1996) (Fig. 1). Eighteen of the $500 \mathrm{~g}$ packs were ' $\mathrm{m}$ ' packs, which had a thermocouple inserted into the geometric centre of the pack. Ambient conditions were monitored by a thermocouple placed $300 \mathrm{~mm}$ to the front of the cabinet and $150 \mathrm{~mm}$ above the lower lip of the canopy of the cabinet. All thermocouples were calibrated T-type (copperconstantan) with an accuracy of $\pm 0.1^{\circ} \mathrm{C}$. Relative humidity was measured to an accuracy of $\pm 3 \% \mathrm{RH}$ using a humidity
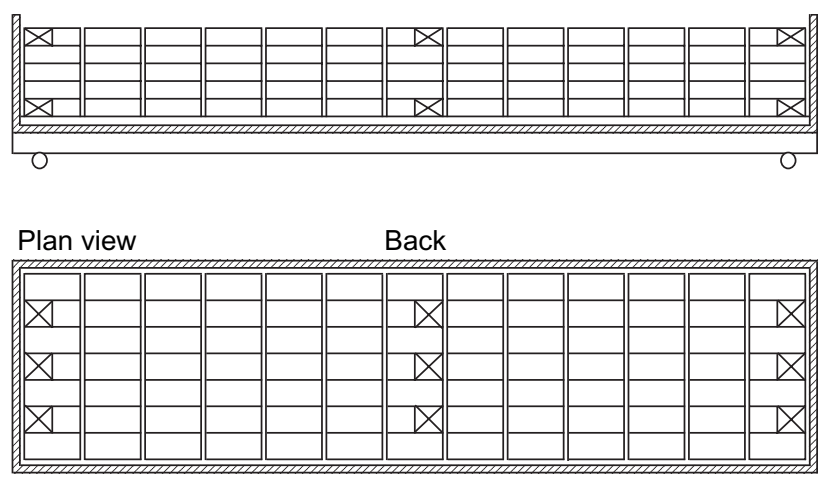

$\bigotimes$ 'm' pack

Fig. 1 - Loading pattern and positions of ' $m$ ' packs in cabinet.

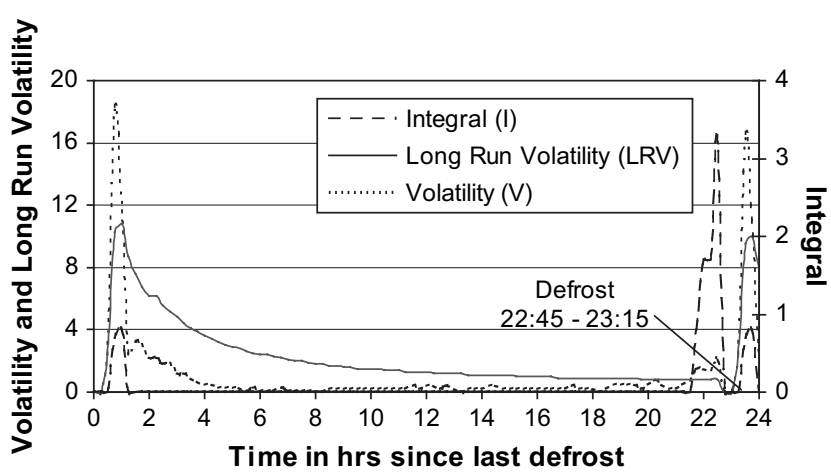

Fig. 2 - Operation of PREDICT algorithm.

meter (Protimeter DDp. $989 \mathrm{M}$ ) placed in the centre of the room and power measured to an accuracy of $\pm 3 \mathrm{~W}$ using a power meter (Northern Design PM390) connected to the stabilised mains electrical supply.

Thermocouples to measure refrigerant temperature were embedded in heat transfer compound (zinc oxide jelled silicone) and strapped tightly to the liquid and suction pipes at entry and exit to the evaporator. The whole pipe was insulated with $25 \mathrm{~mm}$ thick flexible Armaflex for $100 \mathrm{~mm}$ on either side of the measurement points. Pressure was measured to an accuracy of $0.15 \%$ of reading using calibrated strain gauge type pressure transducers. Mass flow was measured using a Danfoss DI6 coriolis mass flow meter. The flow meter was calibrated prior to the tests and was found to be accurate to $\pm 3.5 \%$ of reading.

The temperature of the air and ' $m$ ' packs, relative humidity and power were recorded every minute using a data logging system (Datascan modules, Measurement Systems Ltd.). Refrigerant liquid suction pressure, temperature and mass flow were recorded every $5 \mathrm{~s}$.

\subsection{Validation of the PREDICT algorithm}

The PREDICT algorithm takes the mean superheat (calculated from the evaporating pressure converted to saturated temperature and evaporator suction temperature (R404A, 2001)) measured over 16 consecutive 1 minute periods of refrigerant flow (periods of no refrigerant flow were ignored). These 16 measurements were examined and to eliminate rogue readings, the highest and the lowest omitted. The maximum, $S_{1}$, the

\begin{tabular}{|c|c|c|c|c|c|c|c|}
\hline Replicate & 1 & 2 & 3 & 4 & 5 & 6 & 7 \\
\hline $\begin{array}{l}\text { Hours from } \\
\text { last defrost to defrost } \\
\text { required signal }\end{array}$ & 20.5 & 24.8 & 29.8 & 35.3 & 44.5 & 51.0 & 55.0 \\
\hline $\begin{array}{l}\text { Hours from } \\
\text { last defrost to 'm' pack } \\
\text { mean temperature } \\
\text { exceeding }-12^{\circ} \mathrm{C}\end{array}$ & 51.8 & 40.8 & 46.5 & 43.5 & 54.0 & 73.3 & 83.3 \\
\hline Safety margin (h) & 31.3 & 16.0 & 16.7 & 8.2 & 9.5 & 22.3 & 28.3 \\
\hline
\end{tabular}




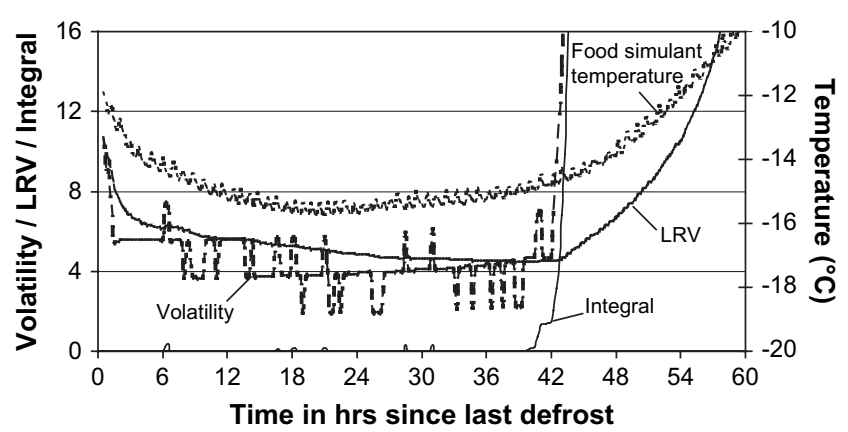

Fig. 3 - Mean ' $m$ ' pack temperature variation with PREDICT defrost requirement indication.

minimum, $S_{2}$, and the mean, $S_{m}$, of the remaining 14 values were calculated.

A value, termed volatility, $\mathrm{V}$ (in \%), was then calculated using Eq. (1) (it should be noted that $V$ can exceed 100\%).

$\mathrm{V}=100 \frac{\left(\mathrm{S}_{1}-\mathrm{S}_{2}\right)}{\mathrm{S}_{m}}$

The Long Run Volatility (LRV) was calculated as the mean of the volatility since the last defrost was calculated. The present volatility was compared with the LRV. Whenever volatility exceeded LRV, a parameter, I, was calculated. This parameter was the sum of the ratios of volatility to LRV minus 1 (Eq. (2)).

$I=\sum\left(\frac{V}{L R V}-1\right)$

'I' was reset to zero whenever the volatility was less than the LRV. 'I' therefore gave a reading of the extent to which the exit superheat had become volatile. When I, reached a certain defined level, it indicated that a defrost was required.

The algorithm was implemented within a time boundary. No defrost was permitted before a certain amount of time had elapsed from the last defrost. This time was typically the same as would normally be used as the defrost interval for a particular cabinet. A defrost maximum period (usually 3-10 times the usual defrost interval) was also defined.

An example of the algorithm operation is shown in Fig. 2. Immediately after a defrost the $\mathrm{V}$ and LRV are high. They then reduce as the heat flows between the cabinet and its environment reaches a steady state. This remains the condition until the evaporator becomes frosted. The volatility then

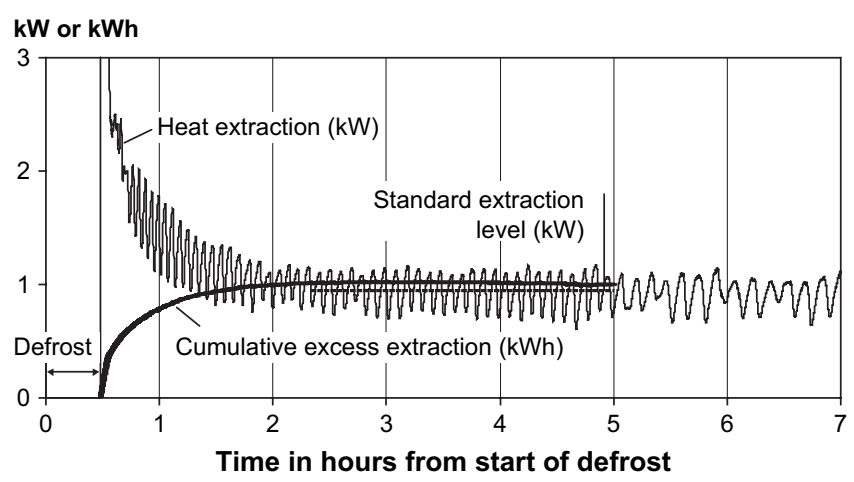

Fig. 4 - Heat extraction after a defrost.

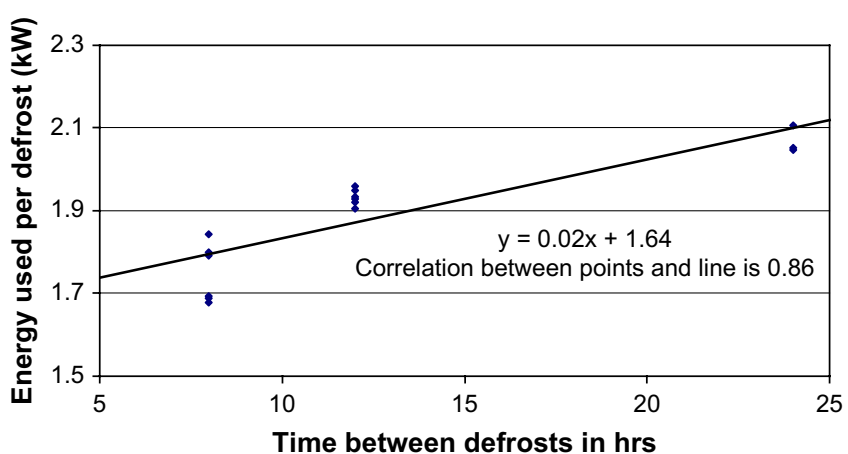

Fig. 5 - Energy used in defrosts with different time gaps between the defrosts.

exceeds the Long Run Volatility at $21.75 \mathrm{~h}$ and 'I' starts climbing. When ' $I$ ' reaches the trip point of 3, a defrost was requested. It was found that the trip point needed to be set at a significant level to avoid responses to noise. The sensitivity of the system, once above the noise level, was not great, as, once the necessary conditions were reached, the value of I increased fast. This is shown and discussed further in Section 3.1.

To validate the PREDICT algorithm a series of seven tests were carried out (tests 1-4 at climate class IV and tests 5-6 at climate class III). Prior to each test the cabinet was defrosted to ensure no ice was present on the evaporator (perspex sight 'windows' were cut into the panels above the evaporator to allow the operator to manually check that no ice was present on the evaporator) and was then run without any defrosts to establish: the times when superheat became volatile compared with the long-term average. After the superheat became volatile the test was terminated, the evaporator defrosted and once ' $m$ ' pack temperatures were stable the test repeated. Product temperatures at the time the PREDICT algorithm would have flagged a defrost were checked to ensure that they had not risen above $-12{ }^{\circ} \mathrm{C}$ (considered as the maximum temperature allowable for frozen food).

\subsection{Defrost energy consumption analysis}

There are two parts to the energy used in a defrost; the direct cost of electrical power into the defrost heaters and the indirect cost of electrical power used to drive the refrigeration in the cabinet to recover after the defrost. The post-defrost refrigeration power can be sub-divided into the heat that has come in from the ambient during the defrost that needs to be removed and the heat that has come from the defrost heaters (i.e. the excess heat not used to melt the ice on the evaporator).

The rate at which heat was transferred from the ambient to the cabinet during defrosts was taken to be the same as would occur under normal operation of the cabinet, i.e. the refrigeration effect:

$Q_{\text {steadystate }}=m\left(h_{2}-h_{1}\right)$

where $m$ is the mass flow of refrigerant, $h_{2}$ is the enthalpy of the refrigerant at the exit of the evaporator and $h_{1}$ is the enthalpy of the refrigerant at the entry of the evaporator. 
During trials stable operation of the cabinet was found to occur during the period from 2 to $5 \mathrm{~h}$ after the start of the defrost.

The refrigeration required to cool the fixtures and food back down to the running temperature was established by calculating the amount of refrigeration required in excess of $\mathrm{Q}_{\text {steady state }}$ during the first $5 \mathrm{~h}$ after defrost. The amount of additional refrigeration power supplied ( $Q_{\text {excess }}$ ) was integrated with time (over the $5 \mathrm{~s}$ measurement period) to produce cumulative excess extraction. The maximum of this integral was taken as the total excess extraction (Eq. (4)).

$Q_{\text {excess }}=\operatorname{Integral}\left(m\left(h_{2}-h_{1}\right)\right)-Q_{\text {steadystate }}$

To determine the energy used in defrosts the cabinet was operated at climate class III and set to defrost at varied time intervals of between 8 and $24 \mathrm{~h}$. In all 14 trials the defrost was set to terminate on temperature to ensure all ice was removed from the evaporator. The length of each defrost and the excess refrigeration effect supplied during recovery were measured for each defrost. From these figures the cost of each defrost in $\mathrm{kWh}$ was calculated. In all calculations a coefficient of performance (COP) for the refrigeration system of unity is assumed (fairly typical for frozen applications).

\section{3. $\quad$ Results}

\subsection{Validation of the PREDICT algorithm}

The results of seven trials showing the mean time interval between defrosts that the PREDICT algorithm flagged and the time for the mean of ' $\mathrm{m}$ ' pack temperatures within the cabinet to reach $-12{ }^{\circ} \mathrm{C}$ are shown in Table 1 . It can be seen that the PREDICT algorithm always gave more than $8 \mathrm{~h}$ warning of a defrost before the mean ' $m$ ' pack temperatures exceeded $-12^{\circ} \mathrm{C}$.

Readings for V, LRV, I and mean ' $m$ ' pack temperature are shown for a typical example in Fig. 3. ' $I$ ', the parameter which indicates the need for a defrost, was set to issue a defrost required signal when it reached 3. The actual value of 'I' was found to be relatively unimportant (provided it was set above a certain level needed to prevent 'noise activation') as once the refrigerant flow became unstable the value of ' $I$ ' increased extremely rapidly. It can be seen that 'I' reached the trip level of 3 at $42.5 \mathrm{~h}$ and the mean ' $\mathrm{m}$ ' pack temperature reached -12 at $54 \mathrm{~h}$. Thus there was a $11.5 \mathrm{~h}$ tolerance between the 'defrost required' signal and the food temperature becoming unacceptably high.

\subsection{Defrost energy consumption}

Fig. 4 shows an example from one test of the heat extracted by the evaporator immediately prior to, and after, a defrost that occurred after $24 \mathrm{~h}$ of refrigeration. The defrost lasted for $29 \mathrm{~min}$ from time 0 . The refrigeration then operated and initially there is a very high extraction rate (approximately $7 \mathrm{~kW}$ ). The heat extraction rate then reduced following approximately an exponential curve and steadied out at the steady state extraction ( $\left.Q_{\text {steady state }}\right)$ of $0.95 \mathrm{~kW}$ in this example. The amount of heat extraction above $Q_{\text {steady state }}\left(Q_{\text {excess }}\right)$ was calculated to be $1.03 \mathrm{kWh}$ in this example.

Therefore the energy consumption during the defrost shown in Fig. 4 was:

\begin{tabular}{lc}
\hline & $\mathrm{kWh}$ \\
Heaters 24 min (29 min defrost time less & 1.52 \\
5 min drain down time) at $3.8 \mathrm{~kW}$ & \\
Less heat flow from ambient during & -0.46 \\
29 min defrost at $0.95 \mathrm{~kW}$ & \\
Excess heat extraction during recovery & 1.03 \\
Energy consumption of defrost in kWh & 2.09 \\
\hline
\end{tabular}

The total energy used in a defrost against the time between defrosts for all 14 tests is shown in Fig. 5.

A reasonably good linear relationship between the total energy used per defrost and the time between defrosts was found. The intercept on the energy per defrost axis $(1.64 \mathrm{~kW})$ was the fixture heating component whilst the gradient of the line was the latent heat energy use to melt the ice on the evaporator $(0.02 \times$ time in $\mathrm{h})$. It is worth noting that fixture heating is double counted as energy has to be used to heat and then again to cool it.

\section{Discussion}

The tests were deliberately performed in higher temperatures and greater humidity than would normally prevail in UK supermarkets. Even so it was found that the mean time for 'defrost required signals' being given was $38.8 \mathrm{~h}$.

The energy used per year for a single $2.5 \mathrm{~m}$ frozen well cabinet with a defrost every $38.8 \mathrm{~h}$ was $538 \mathrm{kWh}$ whereas the energy used with a defrost every $8 \mathrm{~h}$ was $1960 \mathrm{kWh}$. This means that the $38.8 \mathrm{~h}$ defrost represents an energy saving of $72.5 \%$. In a supermarket with 40 cabinets, the annual savings would therefore be $56,880 \mathrm{kWh}$. With an electricity conversion factor of 0.43 , this equates to a saving of 24.5 tonnes of carbon dioxide emission.

It is worth noting that the greatest benefit of increasing the defrost interval is achieved at shorter defrost intervals (Table 2). If a defrost was delayed by $8 \mathrm{~h}$ (from every $8 \mathrm{~h}$ to every $16 \mathrm{~h}$ ) the energy used would be reduced by $46 \%$, however, delaying the defrost for a further $8 \mathrm{~h}$ (i.e. to $24 \mathrm{~h}$ ) would only reduce the energy used by a further $15 \%$. Extending the defrost from 40 to $48 \mathrm{~h}$ only reduced energy use by $3 \%$ and

Table 2 - Effect of extending the time interval between defrosts

\begin{tabular}{lcccccccc} 
Time between defrosts & 8 & 16 & 24 & 32 & 40 & 48 & 60 & 72 \\
\hline Percentage of energy used (\%) & 100.0 & 54.2 & 39.0 & 31.4 & 26.8 & 23.7 & 20.7 & 18.6 \\
Saving (\%) & 0.0 & 45.8 & 61.0 & 68.7 & 73.2 & 76.3 & 79.3 & 81.4 \\
\hline
\end{tabular}


therefore there was less to be gained by extending the defrost period excessively.

\section{Conclusions}

The PREDICT algorithm was found to signal a requirement for a defrost in sufficient time to prevent ' $\mathrm{m}$ ' pack temperatures reaching excessively high levels. It is clear that the ice build up on the evaporator in individual cabinets can vary and therefore a global defrost on demand strategy is unlikely to be successful. Therefore any defrost on demand strategy needs to be applied to individual cabinets and this is possible using the PREDICT algorithm integrated into a commercial supermarket control system.

The cost of a defrost consists of an overhead and an amount of energy to melt the ice. The overhead was found to be around $85 \%$ of the energy used. Because of this, increasing the interval between defrosts achieved substantial savings in energy. By doubling or trebling the time between defrosts more than $45 \%$ or more than $60 \%$ of defrost energy was saved, respectively.

During trials it was noted that an effect of less frequent defrosts was a lower mean temperature of the ' $m$ ' packs. In addition less time was spent by the food at elevated temperatures. The significance of this would depend on the sensitivity of the food to elevated temperatures and sensitivity to fluctuations in temperature.

\section{R E F E R E N C ES}

Axell, M., Fahlen, P., 2002. Climatic influence on display cabinet performance. In: New Technologies in Commercial Refrigeration, Urbana, IL. International Institute of Refrigeration Commissions B2 and D1, pp. 175-184.

Buick, T.R., McMullan, J.T., Morgan, R., Murray, R.B., 1978. Ice detection in heat pumps and coolers. Energy Res. 2, 85-98.

Ciricillo, S.F., 1985. Heat pump de-icing/controlling for energy conservation and costs. In: Proc. Clima 2000 Congress on Heating, Ventilation and Air Conditioning, Copenhagen, pp. 87-92.

Datta, D., Tassou, S., July 2002a. Implementation of a defrost on demand control strategy on a retail display cabinet; new technologies in commercial refrigeration. In: IIR Commissions B2 and D1 Conference at Urbana-Champaign.

Datta, D., Tassou, S.A., Marriott, D., 1998. Experimental investigation into frost formation on display cabinet evaporators in order to implement defrost on demand. In: Proc. 7th International Refrigeration Conference, Purdue, pp. 259-264.

Datta, D., Tassou, S., 1998. Frost formation and demand defrost of display cabinet evaporators. In: IIF-IIR Commission B2 and C2 with D1 and D2/3, Sofia, Bulgaria, 1998/6, pp. 626-632.
Datta, D., Tassou, S.A., Sept. 1999. Defrost control of evaporator coils using artificial intelligence techniques. In: Paper 118, Proc. of the 20th Int. Conf. of Refrig., IIR/IIF, Sydney, Australia.

Datta, D., Tassou, S., 2002b. Implementation of a defrost on demand control strategy on a retail display cabinet. In: Proc. IIF-IIR - Commission D1/B1 - Urbana, IL, USA - 2002/07, pp. 218-226.

EN441-4, 1995. Refrigerated display cabinets. General test conditions. CEN, Eur Stand.

EN441-5, 1996. Refrigerated display cabinets. Temperature test. CEN, Eur Stand.

EN441-6, 1995. Refrigerated display cabinets. Classification according to temperature. CEN, Eur Stand.

EN441-9, 1996. Refrigerated display cabinets. Electrical energy consumption test. CEN, Eur Stand.

EN441-12, 1996. Refrigerated display cabinets. Heat extracted by the evaporator. CEN, Eur Stand.

$\mathrm{Fu}$, B., Labuza, T.P., 1997. Shelf life of frozen foods. In: Labuza, T.P., Fu, B. (Eds.), Shelf Life Testing: Procedures and Prediction Methods. CRC Press, Denver.

Gage, C.L., Kazachki, G.S., July 2002. Warm-liquid defrost for commercial food display cases: experimental investigation at $32.2^{\circ} \mathrm{C}$ condensing. New technologies in commercial refrigeration. In: IIR Commissions B2 and D1 Conference at Urbana-Champaign.

Howell, R.H., Rosario, L., Riiska, D., Bondoc, M., Sept. 1999. Potentials savings in display case energy with reduced supermarket relative humidity. In: Paper 113, Proc. of the 20th Int. Conf. of Refrig., IIR/IIF, Sydney, Australia.

Heinzen, R.A., 1988. How adaptive defrost maintains refrigeration system efficiency. Aust. Refrig. Air Cond. Heat 42 (4), 12-16.

Kuwahara, E., 1985. A relative humidity detection method for use with a room air conditioner. ASHRAE Trans. 91 (Part 2A).

Llewelyn, D.S., 1984. A significant advance in defrost control. Int. J. Refrigeration 7 (5), 334-335.

Lawrence, J.M.W., Parker, B.C., March 2001. Optimising performance and energy use in multi-cold space refrigerating systems. Proc. Inst. Refrig..

Muller, E.D., 1975. A new concept for defrosting refrigeration plants. Kalte 28 (2), 52-54.

Padki, M.M., Sherif, S.A., Nelson, R.M., 1989. A simple method for modelling the frost formation phenomenon in different geometries. ASHRAE Trans. 95 (2), 1127-1137.

Paone, N., Rossi, G., 1991. Fiber-optic ice sensors for refrigerators. Proc. SPIE 1511, 129-139.

R404A - thermophysicalproperties of refrigerants. IIR, France/ 2001 (code BR0404A).

Stribling, D., Tassou, S.A., Marriott, D., 1997. Optimisation of design of refrigerated display cases using computational fluid dynamics. Airah J. 51, 34-44.

Tassou, S.A., Datta, D., Marriott, D., 2001. Frost formation and defrost control parameters for open multideck refrigerated food display cabinets. Proc. Inst. Mech. Eng. 215 (Part A).

Thybo, T., Rasmussen, B.D., Izadi-Zamanabadi, R., 2002. Detecting air circulation faults in refrigerated display cabinets. In: Proc. IIF-IIR - Commission D1/B1 - Urbana, IL, USA - 2002/07, pp. 211-217.

Woodley, C.B.C., Aug 1989. Saving on the defrost. Air Cond. Refrig. News 62. 